BMJ Open Sport \& Exercise Medicine

\section{Push scooter-related injuries in adults: an underestimated threat? Two decades analysed by an emergency department in the capital of Switzerland}

To cite: Mebert RV, Klukowska-Roetzler J, Ziegenhorn S, et al. Push scooter-related injuries in adults: an underestimated threat? Two decades analysed by an emergency department in the capital of Switzerland. BMJ Open Sport \& Exercise Medicine 2018;4:e000428. doi:10.1136/ bmjsem-2018-000428

Accepted 4 September 2018

Check for updates

\section{(C) Author(s) (or their} employer(s)) 2018. Re-use permitted under CC BY. Published by BMJ.

Department of Emergency Medicine, University Hospital, Berne, Switzerland

\section{Correspondence to} Dr Jolanta Klukowska-Roetzler; jolanta.klukowska-roetzler@ insel.ch

\section{ABSTRACT}

Background The number of people conducting cycling and skating sports in Switzerland is rising; likewise, we notice an increase in patients visiting our emergency department for adults due to push scooter accidents. In 2001, our emergency department published the first article worldwide on push scooter-related injuries. Nearly two decades later, we want to review the interim periodcollect data, compare it with other studies and evaluate the current impact of push scooter accidents in our adult patient population.

Objective To investigate data on the incidence, severity, treatment and approximate costs of push scooter-related injuries in adults who presented to our emergency department from 2000 to 2017.

Materials and methods For this descriptive retrospective study, data were collected in the Department of Emergency Medicine at Inselspital (University Hospital), Berne, Switzerland, from October 2000 to September 2017. We used two clinical reporting systems during that period: Qualicare from 2000 to April 2012 and Ecare from May 2012 to 2017.

Results 165 patients were included, aged $16-80$ years. The accidents were mainly classified as unspecified falls in 139 cases (84.24\%). 21 patients (12.73\%) were wearing a helmet at the time of the accident, while the remaining 144 (87.27\%) were not. The most common injuries suffered were fractures in 73 patients (44.24\%). 92 patients (55.76\%) sustained an impact to the head. The most common treatment was surgery in the operating theatre (59 patients, $35.76 \%$ ). The mean total cost per case was SFr7566.65 (emergency room visit, hospital stay and outpatient controls for the initial case).

Conclusion The incidence of push scooter-related injuries in adults in our patient population is small but rising. Nevertheless, the resulting injuries are potentially life-threatening and can lead to persistent medical impairment.

\section{INTRODUCTION}

Approximately 400000 sport accidents happen in Switzerland per year. The Swiss Council for Accident Prevention BFU releases annual accident statistics for Switzerland: The number
What are the new findings?

- The number of adult patients suffering from push scooter accidents in our patient population is small but rising.

- People drive push scooters up until old age; our patient population ranged from 16 to 80 years.

- Injury severity ranges from minor to severe, and fractures of the head and face are the most common.

- Only a small number of patients were wearing helmets at the time of the accident.

How might it impact on clinical practice in future?

Many patients sustained a head impact at the time of the accident, and clinical physicians should pay special attention to neurological findings.

- Severe trauma and death occur without impact at high velocities and patients should be thoroughly examined.

of accidents in 2014 in the section 'other cycling and skating sports' was 10 180, and this number increased from 8120 in $2000 .^{1}$ Likewise we notice an increase in adults visiting our emergency department due to accidents with push scooters over the last years. Nearly two decades have passed since the launch of the first push scooter in Switzerland in 1999. ${ }^{2}$ The Swiss company Micro Mobility Systems AG (Küsnacht, Switzerland) modified the traditional model form of the early $1950 \mathrm{~s}$. The new model is a more lightweight version made of aluminium, weighing less than $5 \mathrm{~kg}$, and easily foldable for convenient transportation and storage. ${ }^{3}$ The technical innovations of the new push scooter compared with the traditional model are the following: it has a narrow base with a high centre of gravity, the wheels are of low friction, made of massive polyurethane and of variable diameter (100-200 mm). Steering is performed with height-adjustable T-handlebars, and braking is performed by pressing one 
foot against the rear-wheel mudguard. ${ }^{2-13}$ These scooters are mainly used by children for recreation, but adults use push scooters for transportation in urban traffic areas and in big building complexes. ${ }^{4}$ In recent years, 'downhill scooters' have become increasingly popular in the Swiss Alpine region. These scooters have larger pneumatic tyres, rather than tyres made of massive polyurethane, so that their owner can ride mountain roads downhill during snow-free seasons. ${ }^{14}$

The sales statistics of Micro Mobility Systems AG from 1999 to 2017 show increasing sales of up to 1000000 units worldwide and a market share of $10 \%$ in 2017 (Marcus Porsche, Deputy CEO, Micro Mobility Systems AG, December 2017). As there are other companies that sell their own models of push scooters, similar increases in their sales can be assumed. We therefore expect that increasing numbers of adults will present to our emergency department due to push scooter accidents.

Paediatric studies have found injuries in different areas of the body: the lower limbs, ${ }^{4}$ the upper limbs, ${ }^{8101315}$ and the head and face. ${ }^{79}$ Wearing a helmet seems to reduce the risk of traumatic brain injury, ${ }^{16}$ but at the same time another study reported a decrease in helmet use with increasing age of the rider. ${ }^{4}$ There is little published information on push scooter-related injuries in adults. Therefore, patient characteristics, injury patterns and optimal treatment for these patients remain unclear.

There are no official guidelines in Switzerland for protective equipment when driving push scooters. The total number of people using protective equipment varies; for example, helmet wear ranges from $4 \%$ up to $40 \%$ in the paediatric population. ${ }^{46121315-17}$ In contrast, injuries involving the head in children have a greater risk of hospitalisation and mortality, and there is always the potential of lifelong negative effects for the patient. ${ }^{18}$ The use of other equipment, such as elbow and knee pads, is estimated to be even lower. ${ }^{12} 1315$

In 2001 our department published the first article worldwide about push scooter-related injuries in Switzerland, under the title The kick with the stick. ${ }^{2}$ Nearly two decades after our first publication, we wanted to look back and collect data on push scooter-related injuries in adults in the interim period. In this study, we describe injury patterns and severity and the management of these patients.

\section{MATERIALS AND METHODS Setting}

The Department of Emergency Medicine at Inselspital (University Hospital), Berne, is the only centre for major trauma treatment in the capital city of Switzerland and commands a catchment area of 1.5 million people. It was reopened in 2012, and is equipped with 3 heliports, 3 emergency trauma rooms for resuscitation (1 with low-dose full-body X-ray (LODOX), 1 dedicated CT scan) and 30 fully monitored examination rooms. In 2017, more than 46000 patients were treated in the department around the clock. ${ }^{19}$

\section{Data collection and retrospective analysis}

This descriptive retrospective study comprised adult patients ( $\geq 16$ years) admitted to our emergency department in Berne due to accidents with push scooters, within the period from October 2000 to September 2017. Younger patients were treated in a separate dedicated paediatric emergency department. A total of 318 cases were collected in that period, of which 165 cases were finally eligible and were further analysed in our study (figure 1). We used two clinical reporting systems during the selected period: from 2000 to April 2012, we worked with Qualicare (Qualicare AG, Trimbach, Switzerland), and from May 2012 to 2017 we recorded emergency cases with Ecare (E.care BVBA, Turnhout, Belgium). Patients were not involved in setting the research agenda.

The inclusion criteria were as follows: direct impact from using a scooter leading to an accident, patient age $\geq 16$ years and presenting to our emergency department in the defined period. Swiss medical policy defines adults as patients of 16 years or older; all patients younger than 16 years are treated at the paediatric emergency department.

Patients under 16 years were excluded, and/or with an indirect impact from a push scooter, for example a pedestrian colliding with another person riding a push scooter.

The following clinical data were extracted from the medical database: diagnosis, circumstances of the accident, sustained type and site of injury, whether a helmet was worn, treatment performed, hospital stay and accruing costs pertaining to the case (emergency room visit, hospital stay and outpatient controls). The diagnosis was categorised as the major injury with the most impact on the patient, and each patient was only allocated to one diagnosis group. If it was not possible to locate one single principal injury, the case was categorised as polytrauma. The treatment was defined as the principal treatment for the major injury or polytrauma previously categorised. No nursing records were consulted. Demographic data such as age and gender were also included, as well as chronological data such as month, day and time of arrival in the emergency department. All clinical records were reviewed by a data manager in our emergency department and patient data were anonymised for the analysis. All duplicate data were removed.

\section{Statistical analysis}

Data were summarised using descriptive statistics (mean, percentages). The figures were prepared with the Microsoft Office Excel and Word programs.

\section{RESULTS}

\section{Patient analysis}

'Trottinett', 'Trotti', 'Trottinet', 'Trottinette', 'Scooter' and 'Scoter' were identified in both databases for 318 patients. One hundred and fifty-three patients were excluded as their admission was not related to direct driving of a push scooter according to the set-up of the study. One hundred and sixty-five cases with scooter 


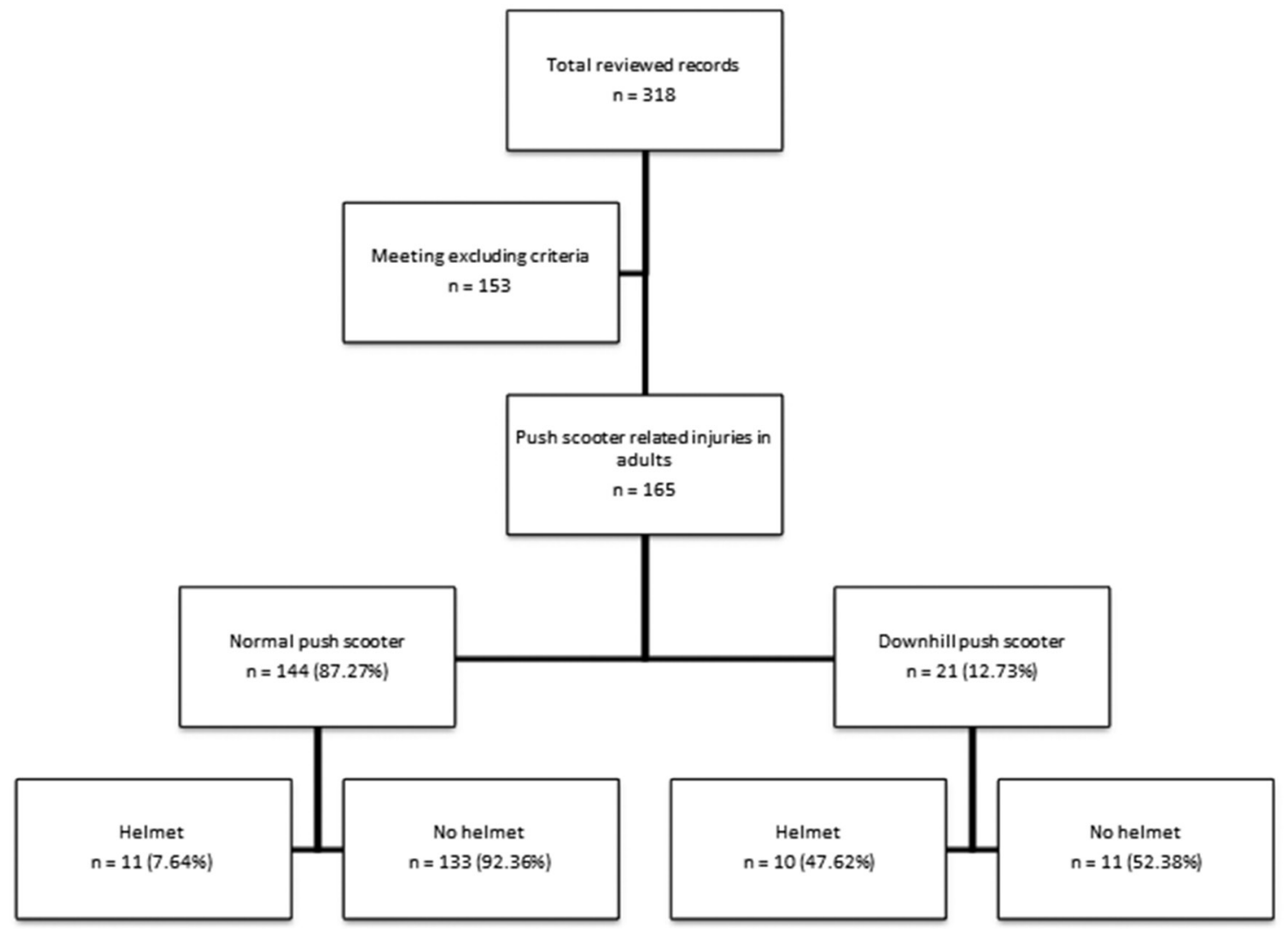

Figure 1 Flow chart of medical record selection.

accidents were eligible for further analyses between October 2000 and September 2017 (figure 1). Table 1 shows the general patient and accident characteristics. Patient age ranged from 16 to 80 years overall, with most accidents for patients aged $38-55$ years.

\section{Accident analysis}

For general accident characteristics, see table 1. Figure 2 shows the annual number of push scooter-related injuries in adults visiting our emergency department in the analysed period. Twenty-four accidents happened in spring (March-May), 75 in summer (June-August), 58 in autumn (September-November) and 8 in winter (December-February). Nearly twice as many accidents occurred between Friday and Sunday than during weekdays. There were no data about the exact time of the accident, but of the arrival time in our emergency department (table 1).

\section{Injury and treatment}

Fractures were the most common injuries, with 73 $(44.24 \%)$ cases, including $21(28.77 \%)$ of the head and face, $18(24.66 \%)$ of the torso, $16(21.92 \%)$ of the upper limbs, $12(16.44 \%)$ of the lower limbs and $6(8.22 \%)$ patients with multiple fractures at various body locations, categorised as polytrauma. The second most common injuries were contusions in $32(19.39 \%)$ patients. Cerebral injuries included traumatic brain injury in $9(5.45 \%)$ patients, subarachnoid haemorrhage in 2 (1.21\%) patients and subdural haematoma in $2(1.21 \%)$ patients.
Sixty-one $(36.97 \%)$ injuries were to the head and face, $34(20.61 \%)$ to the lower limbs, $31(18.79 \%)$ to the torso, $28(16.97 \%)$ to the upper limbs and $11(6.67 \%)$ were to multiple locations of the body and categorised as polytrauma. Figure 3 displays the injured body parts. A total of $55.76 \%$ of all cases sustained impact to the head, despite the location of the main injury. Figure 4 displays the distribution of patients who sustained impact to the head when wearing helmets and their main diagnosis (whole body). Treatment and therapy depended on the patient's injury, but the most common treatment was surgery in the operating theatre, in $59(35.76 \%)$ patients, followed by analgesia in $49(29.70 \%)$ patients.

\section{Hospital stay}

Financial data were obtainable only from the clinical reporting system Ecare (May 2012). The mean cost per case was SFr7566.65, with a range from SFr212.25 to SFr42 146.00 (emergency ER visit, hospital stay and outpatient controls).

\section{DISCUSSION}

\section{Annual number of accidents}

The number of accidents is relatively low in the analysed period. In 2016, for example, a total of 29 patients visited our emergency department because of accidents with push scooters. This corresponds to fewer than three accidents per month. As push scooters are widely used, we can assume that these vehicles are relatively safe and 
Table 1 Characteristics of all patients presented to the emergency with push scooter-related accidents $(n=165)$

\begin{tabular}{lc}
\hline Parameter & Patients, $\mathbf{n}$ (\%) \\
\hline Age (years) & $31(18.79)$ \\
\hline $16-25$ & $87(52.73)$ \\
$25-50$ & $47(28.48)$ \\
$>50$ & \\
Sex & $87(52.73)$ \\
\hline Male & $78(47.27)$ \\
\hline Female & \\
\hline Scooter type & $144(87.27)$ \\
\hline Small-wheeled push scooter & $21(12.73)$ \\
\hline $\begin{array}{l}\text { Pneumatic-wheeled downhill } \\
\text { scooter }\end{array}$ & \\
Helmet worn at the time of the & \\
accident & $21(12.73)$ \\
\hline Helmet & $11(52.38)$ \\
\hline Small-wheeled push scooter & $10(47.62)$ \\
\hline Pneumatic-wheeled downhill scooter & $144(87.27)$ \\
\hline No helmet & $133(92.36)$ \\
\hline Small-wheeled push scooter & $11(7.64)$ \\
\hline $\begin{array}{l}\text { Pneumatic-wheeled downhill } \\
\text { scooter }\end{array}$ & \\
\hline Arval time at the emergency department &
\end{tabular}

Arrival time at the emergency department

\begin{tabular}{|cc|}
\hline 00:00-03:00 & $3(1.82)$ \\
\hline 03:00-06:00 & $3(1.82)$ \\
\hline 06:00-09:00 & $9(5.45)$ \\
\hline 09:00-12:00 & $30(18.81)$ \\
\hline 12:00-15:00 & $24(14.55)$ \\
\hline 15:00-18:00 & $42(25.45)$ \\
\hline 18:00-21:00 & $41(24.85)$ \\
\hline 21:00-24:00 & $12(7.27)$ \\
\hline Unknown & $1(0.61)$ \\
\hline Circumstances & \\
\hline Fall (no other specification) & $139(84.24)$ \\
\hline Loss of control while driving & $9(5.45)$ \\
\hline Slippery underlying surface & $5(3.03)$ \\
\hline $\begin{array}{l}\text { Static handling (eg, folding the scooter } \\
\text { for storage) }\end{array}$ & $4(2.42)$ \\
\hline Misstep while pushing & $3(1.82)$ \\
\hline Car crash & $3(1.82)$ \\
\hline Stumble over an obstacle & $2(1.21)$ \\
\hline Patient referral & \\
\hline Self-referral & $93(56.36)$ \\
\hline Swiss Air Ambulance (REGA, Air & $29(17.58)$ \\
\hline Zermatt, Air Glacier) & $28(16.97)$ \\
\hline Referral from another hospital & $15(9.09)$ \\
\hline Emergency medical service & \\
\hline
\end{tabular}

Continued
Table 1 Continued

\begin{tabular}{lr}
\hline Parameter & Patients, $\mathbf{n}(\%)$ \\
\hline Hospital stay & \\
\hline Inpatient & $59(35.76)$ \\
\hline Outpatient & $106(64.24)$ \\
\hline
\end{tabular}

that they are well handled. This small number of accidents could be the result of the generally low speed with which this vehicle is driven. ${ }^{20}$ After a fall, the acceleration impact to the body would be correspondingly low and the driver would not need any medical check-up. ${ }^{21}$ Another reason could be that there is no need to allow for cars and bicycles in severe traffic, because push scooter drivers are only allowed on pavements in Switzerland. ${ }^{22}$ A third reason could be that patients with minor trauma presented to other hospitals within the catchment area. Nevertheless, the number of push scooter-related accidents in adults in our patient population is increasing, as figure 2 shows. It remains uncertain whether this trend will continue in the future.

The low number of accidents from 2008 to 2010 is striking: Only one person per year visited our emergency department. After several checks of our database, we assume that this low prevalence could be a chance event. The accidents might have been too minor for a visit to a university hospital or patients might have received adequate therapy from a general practitioner. However, there are some fluctuations in prevalence during the analysed period.

\section{Injury severity}

Most of the sustained injuries in our study were minor to moderate. Nonetheless, severe trauma occurred, for example, traumatic brain injury, subarachnoid or subdural bleeding, or complex cranial fractures. Approximately $55 \%$ of patients in our study sustained head impact. The following features of push scooter riding could lead to such a high number: The rider's centre of gravity is positioned relatively near the front wheel as well as relatively high, which increases the risk of tipping over. ${ }^{72}$ Additionally, the small diameter of the wheels may enhance instability while driving over uneven ground and the push scooter may become difficult to manage. ${ }^{371217}$

\section{Helmets}

Only $12.73 \%$ of all patients in our study wore a helmet at the time of the accident. Published data, including data for children, indicate that the range of people wearing a helmet while riding a push scooter is between $4 \%$ and $40 \%{ }^{4}{ }^{4121315-17}$ A push scooter is small and handy and is mostly used by children. ${ }^{411}$ It may therefore appear easier to ride and mislead people into underestimating the dangers in using a push scooter. ${ }^{3}$ The US Consumer Product Safety Commission reported in 2000 a total of $27 \%$ patients with head and face injuries. ${ }^{5}$ Furthermore, 


\section{No. of push scooter accidents in adults visiting our emergency department}

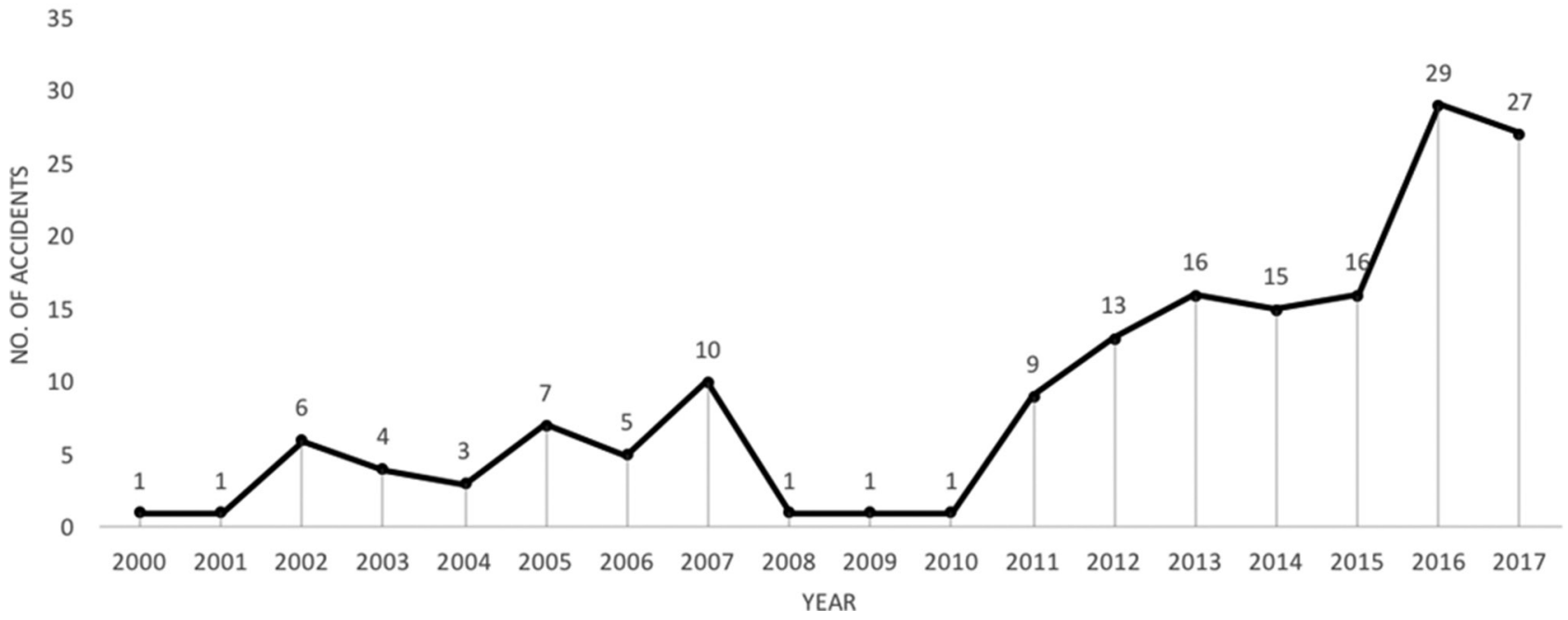

Figure 2 Annual numbers of push scooter-related accidents in the analysed period.

they suggested that $85 \%$ of all head injuries could be prevented by wearing a helmet. Brudvik ${ }^{6}$ reported in 2006 that accidents with push scooters more often lead to head and face injuries than with a skateboard or rollerblades. In 2015, Majercik $e t a l^{16}$ reported that wearing a helmet lowers the incidence of traumatic brain injury in small vehicles.

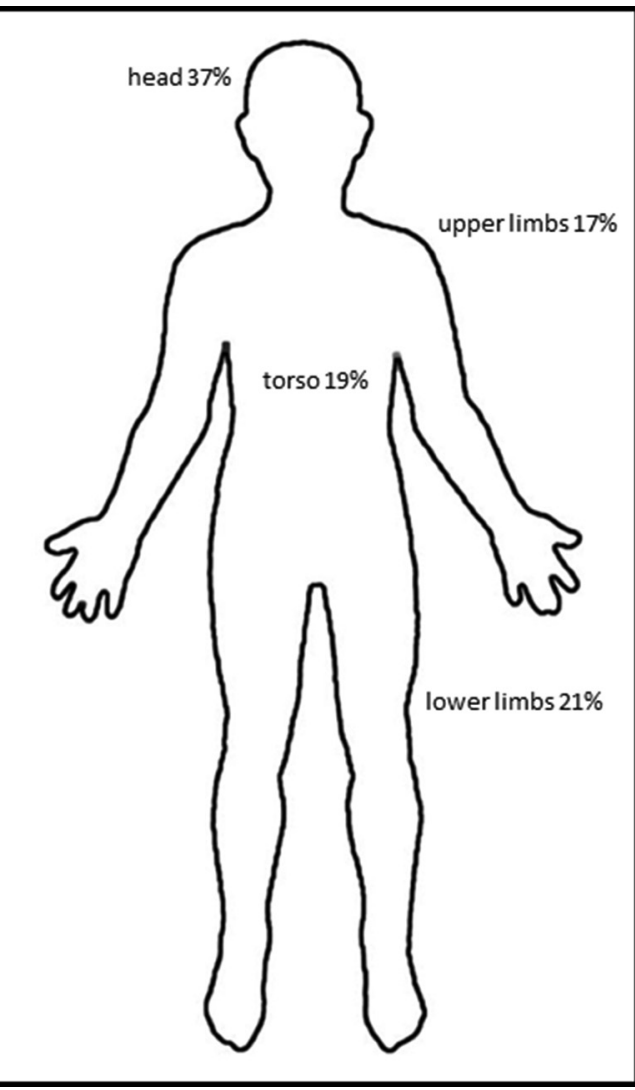

Figure 3 Distribution of injured body parts.

\section{Mortality}

There was no death in our case series. A literature search revealed that lethal incidents do indeed happen: In an article from Parker et $a l^{23}$ in 2004, there were 15 deaths from 1995 to 2001 due to use of push scooters. Most of these were because of head injuries. Not one of these patients wore a helmet. Another study from Kaddis $e t a l^{24}$ in 2016 reported four children who died while using a push scooter.

\section{Paediatric population}

We found the following differences from paediatric studies: According to Baumgartner et at ${ }^{4}$ in 2012, children use a push scooter mainly for recreation and not for transportation. Another difference was in the most common site of injury. In an Australian study conducted by Fong and Hood ${ }^{15}$ in 2004, the most common site was the upper limbs and not the head and face. Similar results were also published by Adeboye and Armstrong ${ }^{8}$ in 2002, Mankovsky et $a l^{10}$ in 2002 and Levine $e t a l^{13}$ in 2001.

\section{Limitations}

The first limitation of this study is its single-centre design. Data were collected from Berne and the surrounding

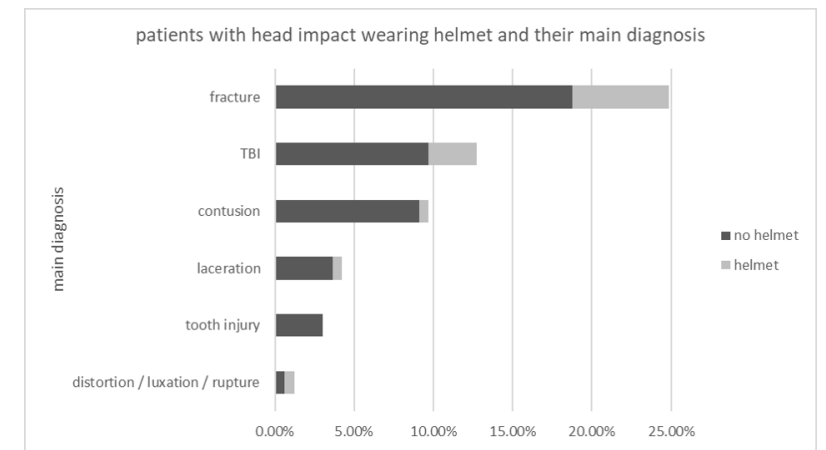

Figure 4 Patients with head impact and helmet wear. TBI, traumatic brain injury. 
catchment area and not from the whole country. Other regions in Switzerland could have different results, as they have more (or fewer) urban traffic areas and therefore more (or fewer) potential users and consecutive accidents.

Second, we collected only data about a patient population with more severe trauma in general. We are a university hospital located in the capital of Switzerland and the severity of injury is assumed to be higher than in peripheral and smaller hospitals. We do not have information about patients consulting general practitioners or with minimal or minor trauma with no need for any special medical consultation. As mentioned in the Results section, some hospitals did transfer their severely injured patients to our emergency department for further diagnostics and treatment.

Third, we worked with two different clinical reporting systems in the analysed period. The quantity and quality of emergency data collection were different-better with Ecare-and the data were even more difficult to compare, as the physicians (Senior House Officers (SHO)/consultant) who entered the data were constantly changing.

Fourth, we collected both data about normal push scooters and the newer downhill scooters. The wheel diameter and material differ in the two models. Therefore, the handling of the push scooter also differs. In a 2012 article on paediatric dental injuries, Baumgartner et $a t^{t}$ reported that scooters with smaller wheels lead to more accidents than those with larger wheels.

Lastly, we analysed data retrospectively. There were no standardised questionnaires to fill and some information was not collected at all. For example, the precise circumstances that led to an accident were mostly not further specified and accidents were only described as fall from push scooter.

\section{CONCLUSION}

The push scooter is a handy and useful vehicle for adults and can be used for various purposes. The incidence of push scooter-related injuries in adults in our patient population is small but has risen over the analysed period. The small number of patients wearing helmets compared with the relatively high number of people sustaining head impact shows the potential threat for severe brain injuries and consequently persistent medical impairment or even death, and might lead to the recommendation of wearing a helmet. Further data need to be collected prospectively to reveal causative factors for severe injuries and how to prevent them.

Acknowledgements We thank Rodney Yeates for his critical English revision of the article.

Contributors Conceptualisation: RVM, JK-R, SZ, AKE. Formal analysis: RVM, JK-R. Investigation: AKE. Methodology: RVM, JK-R, SZ. Project administration: JK-R. Validation: RVM, JK-R. Writing of original draft: RVM. Writing, review and editing: RVM, JK-R, SZ, AKE.

Funding The authors have not declared a specific grant for this research from any funding agency in the public, commercial or not-for-profit sectors.
Competing interests None declared.

Patient consent Not required.

Ethics approval This descriptive retrospective study was approved by the cantonal (district) ethics committee in Berne (no 2018-00149). No individual informed consent was obtained. The analysis was carried out with anonymised data.

Provenance and peer review Not commissioned; externally peer reviewed.

Open access TThis is an open access article distributed in accordance with the Creative Commons Attribution 4.0 Unported (CC BY 4.0) license, which permits others to copy, redistribute, remix, transform and build upon this work for any purpose, provided the original work is properly cited, a link to the licence is given, and indication of whether changes were made. See: http://creativecommons.org/ licenses/by-nc/4.0/.

\section{REFERENCES}

1. BFU. Status 2017, 2017

2. Exadaktylos A, Eggli S, Zimmermann $\mathrm{H}$. The kick with the stick. $\mathrm{Br} \mathrm{J}$ Sports Med 2001;35:276-7.

3. Ho C, Coimbra R, Hoyt DB, et al. Severe traumatic brain injury from unmotorized scooter. J Emerg Med 2001;21:133-6.

4. Baumgartner EN, Krastl G, Kühl S, et al. Dental injuries with kick-scooters in 6- to 12-year-old children. Dent Traumatol 2012;28:148-52.

5. Centers for Disease Control and Prevention (CDC). Unpowered scooter-related injuries--United States, 1998-2000. MMWR Morb Mortal Wkly Rep 2000;49:1108-10.

6. Brudvik C. Injuries caused by small wheel devices. Prev $\mathrm{Sci}$ 2006;7:313-20.

7. Kubiak R, Slongo T. Unpowered scooter injuries in children. Acta Paediatr 2003;92:50-4.

8. Adeboye K, Armstrong L. Pattern and severity of injuries in microscooter related accidents. Emerg Med J 2002;19:571-2.

9. Committee on Injury and Poison Prevention, American Academy of Pediatrics. Skateboard and scooter injuries. Pediatrics 2002;109:542-3.

10. Mankovsky AB, Mendoza-Sagaon M, Cardinaux C, et al. Evaluation of scooter-related injuries in children. J Pediatr Surg 2002;37:755-9.

11. Chapman S, Webber C, O'Meara M. Scooter injuries in children. $J$ Paediatr Child Health 2001;37:567-70.

12. Abbott MB, Hoffinger SA, Nguyen DM, et al. Scooter injuries: a new pediatric morbidity. Pediatrics 2001;108:e2

13. Levine DA, Platt SL, Foltin GL. Scooter injuries in children. Pediatrics 2001;107:E64.

14. Trottiland A, 2017. Available from: http://www.adelboden.ch/en/s/ trottiland [accessed 3 Dec 2017].

15. Fong CP, Hood N. A paediatric trauma study of scooter injuries. Emerg Med Australas 2004;16:139-44.

16. Majercik S, Day S, Stevens MH, et al. Epidemiology of traumatic brain injury after small-wheeled vehicle trauma in Utah. Neurosurgery 2015;77:927-30.

17. Schalamon J, Sarkola T, Nietosvaara Y. Injuries in children associated with the use of nonmotorized scooters. J Pediatr Surg 2003;38:1612-5.

18. Ong JS, Soundappan SV, Adams S, et al. Helmet use in bicycles and non-motorised wheeled recreational vehicles in children. $J$ Paediatr Child Health 2018;54:968-74

19. Universitäres Notfallzentrum: Über uns 2017. 2017. Available from: http://www.notfallzentrum.insel.ch/de/ueber-uns/ [accessed 10 Dec 2017].

20. Reust TJ, 2018. Performance characteristics of two-wheeled pushtype razortm scooters. Available from: http://www.accidentscience. com/razorscooters.pdf [accessed 19 Jan 2018].

21. US NA of EMT. Kinematics of trauma prehospital trauma life support. In: Phtls: prehospital trauma life support. 2014. Available from: http:// www.coursewareobjects.com/objects/evolve/E2/book_pages/phtls/ pdf/PTLS chapter.pdf [accessed 19 Jan 2018]

22. SR 741.11 Verkehrsregelnverordnung vom 13. November 1962 (VRV). 1962. Available from: https://www.admin.ch/opc/de/ classified-compilation/19620246/index.html\#a50 [accessed 19 Jan 2018].

23. Parker JF, O'Shea JS, Simon HK. Unpowered scooter injuries reported to the consumer product safety commission: 1995-2001. Am J Emerg Med 2004;22:273-5.

24. Kaddis M, Stockton K, Kimble R. Trauma in children due to wheeled recreational devices. J Paediatr Child Health 2016;52:30-3. 